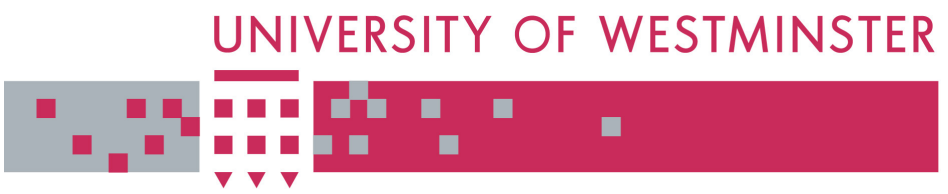

WestminsterResearch

http://www.wmin.ac.uk/westminsterresearch

\title{
Minimizing memory effects in OFDM transmitters using adaptive baseband equalization
}

\author{
Dmytro Bondar ${ }^{1}$ \\ Djuradj Budimir ${ }^{1}$ \\ Boris Shelkovnikov ${ }^{2}$ \\ ${ }^{1}$ School of Informatics, University of Westminster \\ ${ }^{2}$ National Technical University of Ukraine
}

Copyright (C) [2008] IEEE. Reprinted from 18th International Crimean Conference "Microwave \& Telecommunication Technology" (CriMiCo'2008). 8-12 September, Sevastopol, Crimea, Ukraine. IEEE, Los Alamitos, USA, pp. 272-275. ISBN 9789663351698.

This material is posted here with permission of the IEEE. Such permission of the IEEE does not in any way imply IEEE endorsement of any of the University of Westminster's products or services. Personal use of this material is permitted. However, permission to reprint/republish this material for advertising or promotional purposes or for creating new collective works for resale or redistribution to servers or lists, or to reuse any copyrighted component of this work in other works must be obtained from the IEEE. By choosing to view this document, you agree to all provisions of the copyright laws protecting it.

The WestminsterResearch online digital archive at the University of Westminster aims to make the research output of the University available to a wider audience. Copyright and Moral Rights remain with the authors and/or copyright owners.

Users are permitted to download and/or print one copy for non-commercial private study or research. Further distribution and any use of material from within this archive for profit-making enterprises or for commercial gain is strictly forbidden.

Whilst further distribution of specific materials from within this archive is forbidden, you may freely distribute the URL of the University of Westminster Eprints (http://www.wmin.ac.uk/westminsterresearch).

In case of abuse or copyright appearing without permission e-mail wattsn@wmin.ac.uk. 


\title{
MINIMIZING MEMORY EFFECTS IN OFDM TRANSMITTERS USING ADAPTIVE BASEBAND EQUALIZATION
}

\author{
Dmytro Bondar ${ }^{1}$, Djuradj Budimir ${ }^{1}$ and Boris Shelkovnikov ${ }^{2}$ \\ 1-Wireless Communication Research Group, University of Westminster \\ 115 New Cavendish Street, London, UK, W1W 6UW \\ 2-National Technical University of Ukraine ("KPI") 130 \\ 37 Pobedy Avenue, Kiev, Ukraine, 03056 \\ E-mail:bshelk@gmail.com /D.Bondar1@westminster.ac.uk
}

\begin{abstract}
This paper presents a simple and effective approach for eliminating memory effects in OFDM transmitters. It uses advantages of OFDM systems to provide pre-compensation of the frequency-dependent distortions, which are results of the power amplifiers (PA) memory effects. The process of memory effects quantification is carried out in this paper by obtaining a frequency-dependent PA gain, phase shift and intermodulation products. The memory effects are eliminated at baseband using equalization of the IDFT signal. Implementation of the equalization procedure at baseband makes the process of minimizing memory effects simple and effective, because no additional RF components or feedback loops are used. Memory effects are compensated in DSP part using simple multiplication of the frequency-domain digital signal by coefficients, which are calculated adaptively for each OFDM sub-carrier frequency and input power. The approach is tested with Motorola MOSFET MRF9742 power amplifier model in Advanced Design System (ADS). Simulations show significant improvement in minimizing memory effects. Received constellation of the 16-QAM OFDM signal after implementing baseband pre-compensation technique looks alike ideal one whereas without pre-compensation it shows high dispersion due to the presence of PA memory.
\end{abstract}

\section{Introduction}

The real characteristics of power amplifiers often differ from their polynomial models [5]-[6], [11]. This is caused by the dependence of PA output not only on the input but also on the previous input signals, called "Memory Effects" [11].

Memory effects are divided into electrical and thermal [6], [12]. Electrical memory effects appear because node impedances depend on frequency and there are several distortion sources in an amplifier. Therefore, distortion components produced by the different nodes have frequency-varying baseband, fundamental, second, third and other harmonics, which form the frequency-dependent behaviour of the amplifier. Thermal memory effects are caused by the fact that self-heating and environmental changes modify the temperature-dependent electrical characteristics of transistors. In other words, varying signal strength and environmental temperature causes thermal memory effects [6], [13]

Works [3], [6], and [13] show, that thermal memory affects low modulation frequencies and electrical memory influences the high-frequency performance. It means that the impact of thermal memory is more important for narrow-band systems. For wideband systems such as WiMax the main frequency-dependent distortion is caused by the electrical memory effects [13]

Current work aims to minimize memory effects in OFDM WiMax system. Therefore, advantages of OFDM system, such as IDFT, are used. Section 2 describes the process of quantifying memory effects in a real power amplifier system. It determines frequency-dependent gain and phase shift, which are used for calculating equalization function to minimize memory effects by digital operations with baseband IDFT signal. Section 3 describes the adaptive baseband equalization approach for minimizing memory effects in OFDM transmitters. It uses transistorlevel model of a MOSFET power amplifier in ADS simulations for verification performances of the considered method.

272

\section{Quantifying Memory Effects}

To quantify memory effects several methods have been proposed [3-6], [11-12]. Dependence of the magnitude and phase of intermodulation products IM3 on tone spacing as well as a gain dependence on the modulation frequency indicates the presence of memory. Distortion of a constellation diagram at the PA output when it operates in a linear mode is also a consequence of memory effects.

This paper presents a quantification and elimination of memory effects for a power amplifier using the developed baseband equalization approach. To demonstrate performance of the proposed method, ADS transistor-level model of a MOSFET power amplifier MRF9742 has been used for simulations. The current section presents results of MRF9742 simulations. It demonstrates presence of memory effects by a frequency-dependent gain, IMD and distorted constellation in a linear mode. Section 3 describes the proposed baseband equalization approach and verifies it by simulations.

Matlab-ADS co-simulation system has been used for simulations. Motorola MOSFET model showed on Fig. 1 was used as an active device in ADS analog circuit for a PA exhibiting memory effects. OFDM signal source was implemented in Matlab code and called from ADS. Such approach allows providing convenience and flexibility in generation any kind of input signal by using Matlab signal source, where desired equalization approach can be easily implemented.

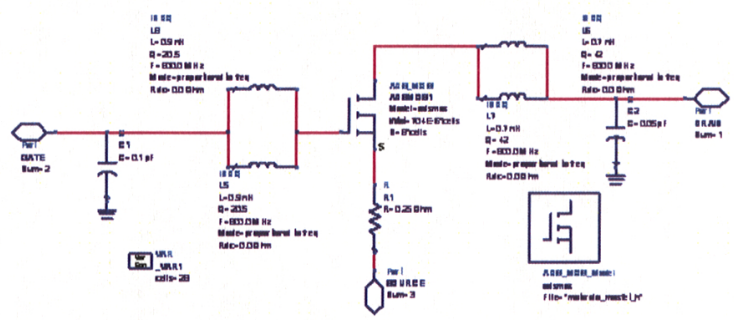

Figure 1. Motorola MOSFET model for ADS simulations

Results of the simulations are presented on Fig. 2-7. Fig. 2 shows gain dependence versus output power at different input frequencies for the investigated power amplifier. MRF9742 has a 12-dB gain and a $25-\mathrm{dBm}$ compression point. In order to quantify only memory effects but not a saturation, the power range for further simulations has been chosen as Pout $=0 \ldots 15 \mathrm{dBm}$. The tone difference for two-tone tests was taken in range of $10 \mathrm{kHz}$ $-30 \mathrm{MHz}$. Variation of the gain over frequency indicates presence of memory effects. This is more visually demonstrated on Fig. 3, where the gain versus frequency is presented. This distortion also depends on a power level. For Pout $=0 \mathrm{dBm}$ the gain is almost independent of the modulation frequency whereas for Pout $=15 \mathrm{dBm}$ it is significantly varying. In a memoryless amplifier there is no 
phase change for the fundamental signal and intermodulation products IM3 [4]. Moreover, IM3 magnitude is proportional to the input power only and is independent of frequency. Therefore, varying phase and IM3 magnitude are often used to quantify memory effects [4]-[6].

Fig. 4 demonstrates a variation of the fundamental signal phase over modulation frequency due to memory effects.

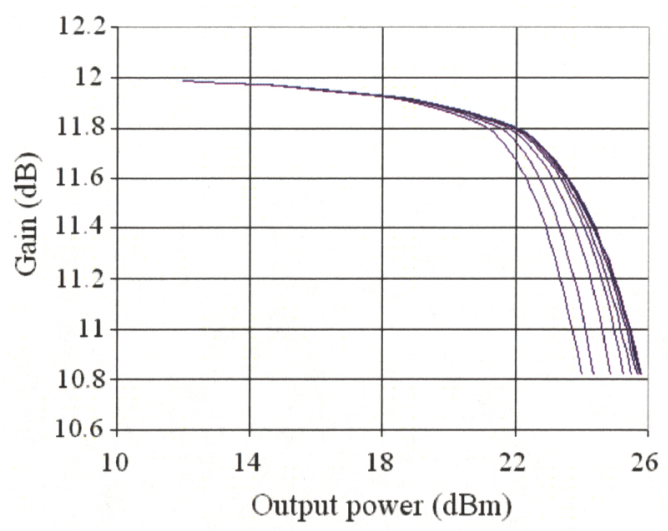

Figure 2. Simulated MRF9742 gain for different modulation frequencies $(10 \mathrm{kHz}-30 \mathrm{MHz})$

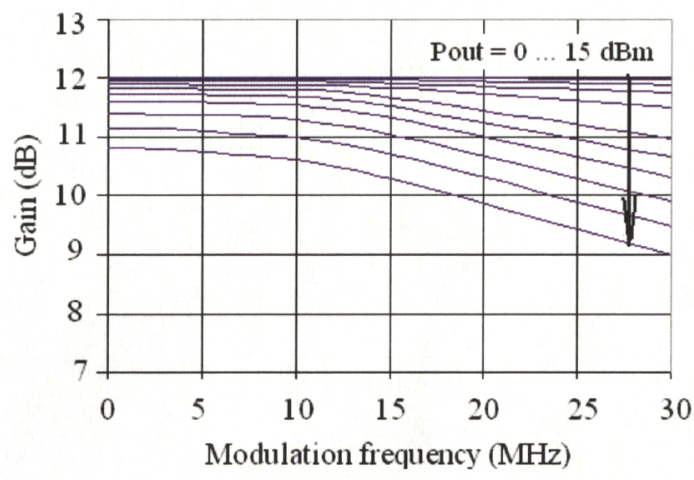

Figure 3. Simulated MRF9742 gain variation due to memory effects

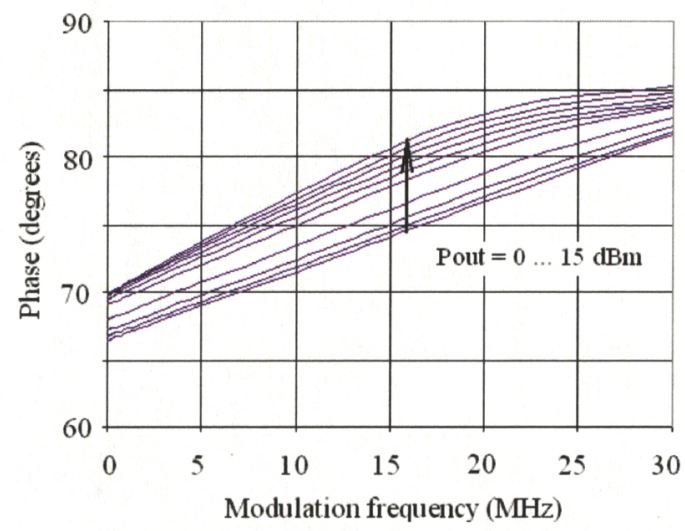

Figure 4. Simulated MRF9742 phase variation due to memory effects

3D-plots of the IM3 magnitude and phase are shown on Fig. 5 and Fig. 6 respectively. The variations over frequency indicate memory effects. Finally, a received con- stellation for 16-QAM signal at Pin $=-5 \mathrm{dBm}$ is presented on Fig, 7. The constellation is distorted due to memory effects because the power amplifier operates in a linear mode and all the other components are taken ideal.

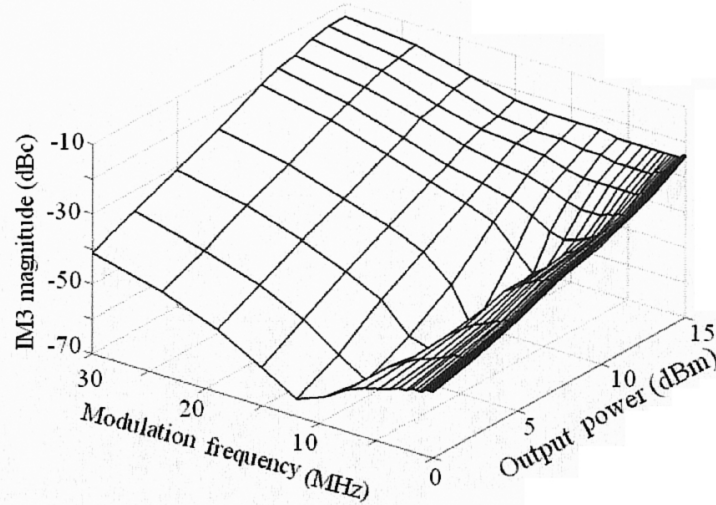

Figure 5. Simulated MRF9742 IM3 magnitude versus power and frequency

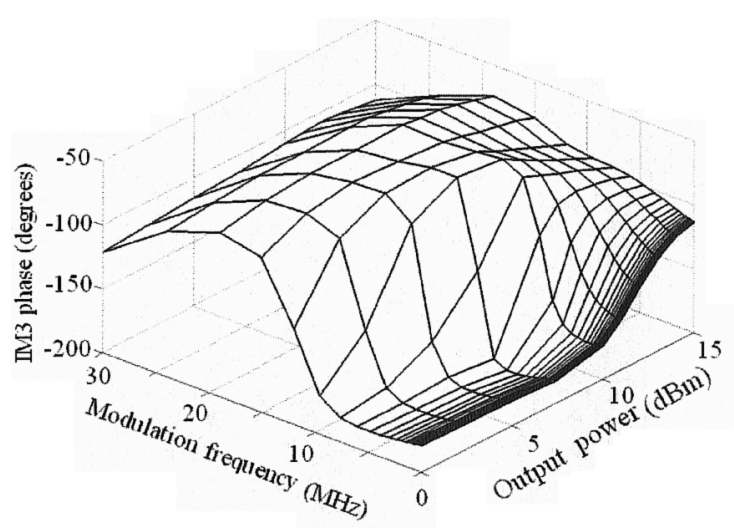

Figure 6. Simulated MRF9742 IM3 phase versus power and frequency

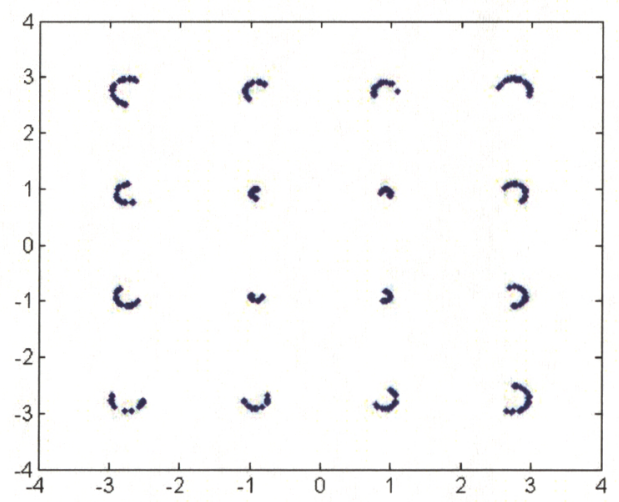

Figure 7. Received constellation distortion due to the memory effects (Pin $=-5 \mathrm{dBm}$ )

\section{Baseband Equalization Method}

Power amplifiers with memory effects are usually modelled by a filter and a non-linear element connected in series [1], [7-11]. If the filter precedes the non-linear block

2008 18th Int. Crimean Conference "Microwave \& Telecommunication Technology" (CriMiCo'2008). 8-12 September, Sevastopol, Crimea, Ukraine 
this is a Wiener model; otherwise it is a Hammerstein model. In this work a Wiener model for a power amplifier is considered (Fig. 8). The non-linear block is usually represented by the polynomial model described in [14]. The filter characterizes source of a frequency-dependent behaviour or memory effects. Therefore, to compensate for the memory effects it is necessary to analyze the filter. It has a frequency response which depends on the input power level $H(f, P$ in $)$

To compensate for the memory-related distortions, equalization is usually used. Advantages of OFDM signals such as IDFT allow to make this equalization at baseband by simply multiplying the IDFT inputs by $1 / H(f, P i n)[2,7,8]$.

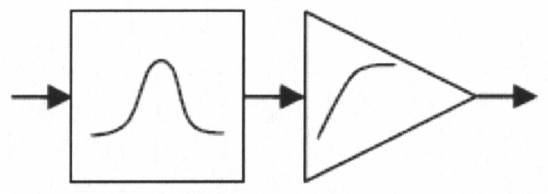

Figure 8. Wiener model for $P A$

There are several challenges in this approach, which need to be solved before implementing this method to a particular amplification system.

First of all, $H(f, P$ in) should be normalized in order not to affect the mean power level.

Secondly, to make the equalization system adaptive to the input power level, the frequency response of the filter at all possible power values should be calculated and stored in an index table.

Then the frequency response $H(f, P$ in), corresponding to the input power level will be taken from the index table for pre-compensation. In the case of 16-QAM there are 4 possible levels of $I$ and $Q$ signals $(-3,-1,1,3)$. As baseband power is proportional to $I^{2}+Q^{2}$, there are 3 possible values of the input power corresponding to: $1^{2}+1^{2}, 3^{2}+1^{2}$ and $3^{2}+3^{2}$. For the case of 64-QAM there are 8 levels for I and $Q$ signals and therefore, 10 possible values for the input power. For those values frequency response of the filter should be tabulated.

For the case of considered MRF9742 power amplifier the process of baseband equalization is described bellow with an example of 16-QAM input signal.

The magnitude and phase of the normalized filter frequency response are extracted from the gain and phase curves for MRF9742 (Fig. 3, 4). The baseband signal levels chosen for the simulation are presented in Table I. At these levels, the amplifier exhibits memory effects, but it is not in saturation. As a 16-QAM input is considered, baseband signal has 3 possible magnitude values (Tab. I)

The WiMax 64-OFDM 16-QAM system is used. For baseband power $P \mathrm{bb}=-20.8 \mathrm{dBm},-6.8 \mathrm{dBm}$ and $-1.7 \mathrm{dBm}$ the normalized complex values $H$ norm $(f, P$ in) are calculated using the obtained gain and phase dependences (Fig. 3,4$)$. Magnitude and phase of the normalized frequency response for the considered 16-QAM modulation are presented on Fig. 9, 10 respectively.

To compensate for the memory effects, the complex baseband signal was multiplied by $1 / H n o r m(f, P i n)$. After that, IDFT was performed and an OFDM waveform was created. It passed MRF9742 amplifier at a mean input power level of $-5 \mathrm{dBm}$. The received constellation was obtained (Fig. 11). Comparing with the constellation at Fig. 24, dispersion due to the memory effects is almost eliminated, which characterizes that the frequency response $H$ norm( $f, P$ in) is calculated accurately and the baseband equalization is performed correctly.
TABLE I

Voltage and Power Levels for Simulations

\begin{tabular}{|c|c|c|c|}
\hline $\begin{array}{c}m a g(\mathrm{I}), \\
\mathrm{V}\end{array}$ & $\begin{array}{c}\text { mag(Q), } \\
\mathrm{V}\end{array}$ & $\begin{array}{c}\text { mag( } \mathrm{Vbb}), \\
\mathrm{V}\end{array}$ & $\begin{array}{c}\text { mag(Pbb), } \\
\mathrm{dBm}\end{array}$ \\
\hline 0.12 & 0.12 & 0.03 & -20.81 \\
\hline 0.12 & 0.36 & 0.14 & -6.83 \\
\hline 0.36 & 0.36 & 0.26 & -1.73 \\
\hline
\end{tabular}

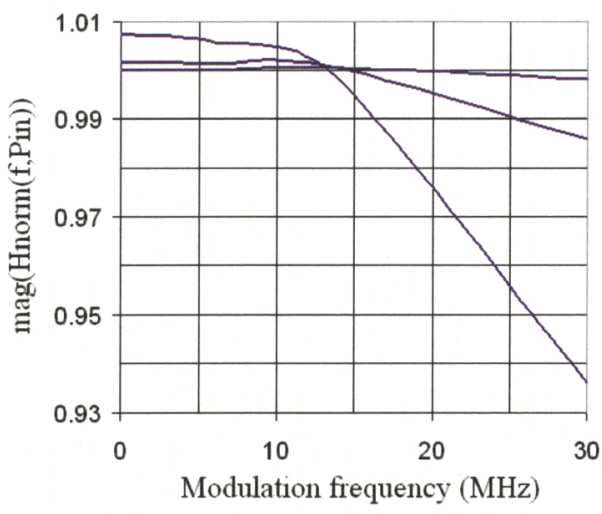

Figure 9. Magnitude of the normalized frequency response Hnorm(f, Pin) for 3 power levels of 16-QAM

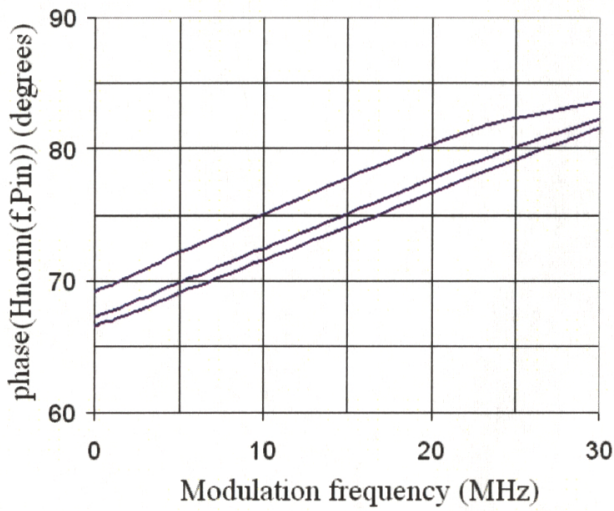

Figure 10. Phase of the normalized frequency response Hnorm(f, Pin) for 3 power levels of 16-QAM

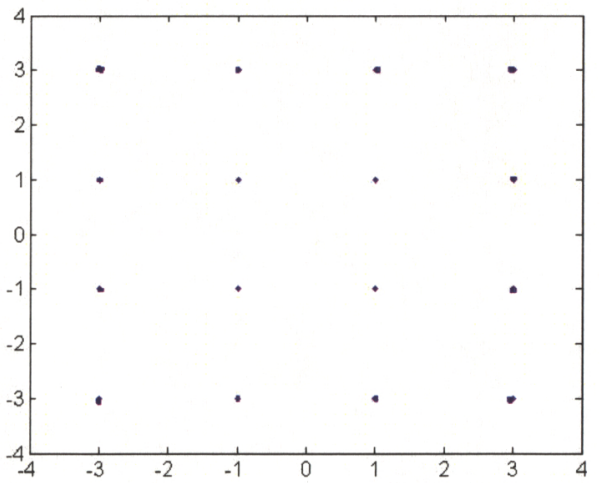

Figure 11. Simulated received constellation for MRF9742 using baseband equalization (Pin $=-5 \mathrm{dBm}$ ) 


\section{Conclusion}

A baseband equalization approach for minimizing memory effects has been presented in this paper. It uses digital pre-compensation of the input signal at baseband before IDFT in OFDM waveform. The proposed method was verified by Matlab-ADS co-simulation of the transceiver based on Motorola MOSFET MRF9742 active device. Simulation results proved good performance of the method in eliminating memory effect of the power amplifier. Quantification of the memory effects was performed by obtaining frequency-dependent gain, phase and IM3 performances of the PA. It was shown, that memory effects have high influence on the dispersion of the received constellation. After implementing proposed approach, significant improvement in received constellation for the same power level has been achieved. The baseband equalization method is a simple, low-cost, easily implemented technique, which is performed at DSP part and does not require additional components or hardware change in RF part. Described advantages make the method favourable for minimizing memory effects in OFDM systems.

\section{References}

[1] J. C. Pedro and S. A. Maas, "A comparative overview of microwave and wireless power amplifier behavioral modeling approaches", IEEE Trans. Microwave Theory Tech., vol. 53, pp. 1150-1163, 2005

[2] R.van Nee and R.Prasad, OFDM for Wireless Multi- media Communications, Artech House Publ., 2000

[3] J. Vuolevi, J. Manninen, and T. Rahkonen, "Canceling the memory effects in RF power amplifiers", in Int. Circuits and Systems Symp., vol. 1, May 6-9, 2001, pp. 57-60

[4] J. Vuolevi, J. Manninen, and T. Rahkonen, "Memory effects compensation in RF power amplifiers by using envelope injection technique," Radio and Wireless Conf. Dig., Aug. 2001 , pp. 257-260.

[5] J. Vuolevi, T. Rahkonen, "Analysis of amplitude-dependent memory effects in RF power amplifiers", European Conference on Circuit Theory and Design ECCTD'01, Espoo, Finland August 28-31, 2001, pp. 37-40.

[6] J. Vuolevi, T. Rahkonen, and J. Manninen, "Measurement technique for characterizing memory effects in RF power amplifiers", IEEE Trans. Microwave Theory Tech., vol. 49, pp. 1383-1389, 2001

[7] A. Chaker, M. Ariaudo, I. Fijalkow, J.-L Gautier, "Precompensation of the frequency-dependence of a non-linear amplifier in a multi-carrier transmission", IEEE Internationa Conference on Communications ICC'04, June 2004, Paris

[8] A. Chaker, M. Ariaudo, S. Traverso, J.-L. Gautier I. Fijalkow, "Adaptive compensation of high frequency memory effects of a realistic amplifier in an OFDM system", IEEE International Conference on Information \& Communication Technologies: from Theory to Applications (ICTTA'06), Damas, Syria, April 2006.

[9] T. Wang and J. llow, "Compensation of nonlinear distortions with memory effects in OFDM transmitters", in Proc. IEEE Global Telecomm. Conf., vol. 4, pp. 2398-2403, Nov. 2004

[10] J. Moon, Jangheon Kim, I. Kim, Jungjoon Kim, and B. Kim, "A wideband envelope tracking Doherty amplifier for WiMax systems", IEEE Microwave and Wireless Components Letters, vol. 18 , no. 1, pp. $49-51$, Jan. 2008
[11] W. Huadong, W. Zhengde, B. Jinfu, T. Xiaohong, "Analyzing memory effect in RF power amplifier using three-box modeling", APMC 2005. Asia-Pacific Conference Proceedings, Volume 4, 4-7 Dec. 2005

[12] W. Bosch and G. Gatti, "Measurement and simulation of memory effects in predistortion linearizers", IEEE Trans. MTT, Vol. 37, No. 12, pp. 1885-1890, Dec. 1989

[13] T. Liu, S. Boumaiza, and Fadhel M. Ghannouchi, "Identification and pre-compensation of the electrical memory effects in wireless transceivers", 2006 Radio \& Wireless Symposium (RWS-2006), San Diego, USA, pp. 535-538, January 2006.

[14] D. Bondar, and D. Budimir, "WiMax Power Amplifier Linearisation Through Injection of Base-Band Component", 11h International Symposium on Microwave and Optical Technology (ISMOT-2007), Roma, Italy, 17 - 21 December 2007.

\section{МИНИМИЗАЦИЯ ЭФФЕКТОВ ПАМЯТИ В ПЕРЕДАТЧИКАХ ОFDМ ПУТЕМ АДАПТИВНОГО ВЫРАВНИВАНИЯ ПО ЧАСТОТЕ МОДУЛИРУЮЩЕГО СИГНАЛА}

\author{
Бондарь Д. Б. ${ }^{1}$, Будимир Д. ${ }^{1}$, Шелковников Б. Н. ${ }^{2}$ \\ 1-Вестминстерсий Университет \\ 115 Нью Кавэндиш Cтрит \\ Лондон, Великобритания, W1W 6UW \\ 2-Национальный Технический Университет \\ Украины «КПИ» \\ пр. Победы 37, Киев, Украина, 03056 \\ e-mail: D.Bondar1@westminster.ac.uk
}

Аннотация - Данная статья описывает простой и эффективный подход для устранения эффектов памяти в передатчиках OFDM. Преимущества ортогональной частотной модуляции используются для прекомпенсации частотно зависимых искажений, являющихся результатом эффектов памяти в усилителях мощности. Процесс количественной оценки эффектов памяти выполнен в статье путем получения частотно зависимых характеристик усиления, фазового сдвига и интермодуляционных продуктов. Эффекты памяти устраняются с помощью частотного выравнивания дискретного ОПФ модулирующего сигнала. Реализация процедурь на уровне модулирующего сигнала упрощает и делает более эффективным процесс устранения зффектов памяти, поскольку не используются дополнительные РЧ компоненты и цепи обратной связи. В блоке ЦОС производится простое умножение в частотной области сигналов на коэффициенты, которые адаптивно рассчитываются для каждого значения частоты и входной мощности вспомогательной несущей OFDM. Предложенный метод протестирован на модели усилителя мощности компании Motorola, построенного на полевом транзисторе с МOП-структурой MRF9742 в программе ADS. Результаты моделирования показали существенное уменьшение эффектов памяти. После внедрения метода частотного выравнивания модулирующего сигнала вид принятой звездной диаграммы сигнала 16-QAM OFDM близок к идеальному, в то время как без примени данного метода наблюдается значительное рассеивание звездной диаграммы из-за наличия эффектов памяти. 